\title{
Dos diagnósticos aos manuais: mercado farmacêutico e transtornos mentais da infância em questão
}

Marcia da Silva Mazon (UFSC)'

\section{Resumo}

O intuito do artigo é situar o momento de mudança - tanto nos artigos como nos procedimentos de pesquisa - que marca o DSM-III enquanto forma de abordagem dos transtornos psiquiátricos situando a indústria farmacêutica na conformação de novos discursos. Este é o momento da reemergência do Distúrbio de Déficit de Atenção e Hiperatividade (TDAH) e marca o confronto com a abordagem psicodinâmica freudiana que será secundada pela alternativa de testes e procedimentosestatísticos. Qual o contexto destas transformações? Mobilizamos autores da sociologia econômica para pensar o mercado de medicamentosenquanto campo de lutas - luta em torno dos critérios de classificação da realidade -bem como a dinâmica de interatuação com o campo da saúde. $\mathrm{O}$ artigo parte de pesquisa bibliográfica e análise documental. $\mathrm{O}$ argumento é o de que a nosologia do TDAH, como qualquer outro arbitrário cultural, não é neutra e expressa relações de poder. Se diversas pesquisas apontam o poder médico como poder biopolítico, é possível constatar como novos arranjos entre indústria farmacêutica e psiquiatria ampliam o espaço de atuação da primeira alcançando adolescência e infância somando a atuação da indústria farmacêutica como reforço biopolítico.

Palavras-chave: Mercado. Diagnóstico. Transtornos mentais da infância. TDAH. Indústria farmacêutica.

I Doutora em Sociologia Política pela Universidade Federal de Santa Catarina (UFSC), Florianópolis/SC, Brasil. Éprofessora associada do Departamento de Sociologia e Ciência Política na mesma Universidade, do Programa de Pós-Graduação em Sociologia e Ciência Política, onde coordena o Núcleo de Sociologia Econômica (Nusec). Agradeço a CAPES o apoio através do projeto de convênio internacional CAPES COFECUB: $A$ disseminação dos saberes espertos no domínio da Infância, no qual a presente pesquisa está integrada. E-mail: marciadasilvamazon@yahoo.com.br

Direito autoral e licença de uso: Este artigo está licenciado sob uma Licença Creative Commons. Com essa licença você pode compartilhar, adaptar, para qualquer fim, desde que atribua a autoria da obra, forneça um link para a licença, e indicar se foram feitas alterações. 


\section{Introdução: nosologia, medicamentos e mercados}

Estudos recentes focam as relações entre empresas farmacêuticas e a psiquiatriabem como sua interação com indivíduos e seus corpos na inauguração de novos produtos no mercado. Alguns autores observam o poder excepcional da indústria de fármacos, em particular os psicotrópicos, atribuindoa esta a capacidade de manipular necessidades e desejos coletivos, em particular quando o assunto são os medicamentos para transtornos mentais (PETRYNA; LAKOFF;KLEINMAN, 2006; HEALY, 2006; WHITAKER, 2017). O advento da nova psiquiatria biomédica de um lado é comemorado como resultado de descobertas científicas que levarão a descobertas médicas; de outro, é criticado como uma forma sinistra de controle social ligada a uma perda de autonomia e responsabilidade pessoal (LAKOFF, 2002; CAPONI, 2014, 2019). Igualmente a nova psiquiatria biomédica torna a indústria farmacêutica poderosa: as drogas psiquiátricas são "a maior fonte de renda" dos fabricantes do setor (FRANCES, 2016, p. 15).

$\mathrm{O}$ assunto ganha tons mais fortes quando o objeto são os transtornos mentais da infância ou a epidemia do Distúrbio de Déficit de Atenção e Hiperatividade (TDAH) capitaneada pela promoção, demanda e abuso deRitalina e Adderal $^{\circ}$ nas escolas secundárias americanas - fenômeno ampliado nas últimas décadas. A situação não é muito diferente no Brasil, segundo país maior consumidor de psicotrópicos na infância, em particular metilfenidado(Ritalina) (CAPONI, 2014, 2016, 2019). Conforme Lakoff (2000), nos EUA mais frequentemente os pais do que pediatras ou psiquiatras estão buscando diagnósticos para seus filhos. Igualmente no Brasil ganha impulso na última década a discussão legal de iniciativas que defendem a psiquiatrização da infância, exemplos de Santa Catarina e do Rio Grande do Sul onde alguns municípios encaminharamprojetos de leis municipais de prevenção, detecção precoce e diagnóstico de transtornos mentais na infância ${ }^{2}$ (CAPONI, 2019, p. 190).

2 Importante considerar que, a partir das críticas da IX Conferência Nacional de Saúde em 1992, haverá uma reforma no Sistema Único de Saúde (SUS) no Brasil. Esta reforma desloca para os municípios o papel gestor da saúde e será responsabilidade dos municípios coordenarem os serviços de saúde na medida em que há uma generalização da transferência automática de recursos para ao âmbito municipal (VIANA, 2000, p. 129). 
O intuito deste artigo é contribuir com estas reflexôessobre aindústria farmacêutica e sua relação com os novos diagnósticos psiquiátricos e iniciativas da área médica, observando o fenômeno a partir da perspectiva dos mercados. Embora o tratamento farmacêutico seja central para psiquiatria biomédica atual, é importante enfatizar que o desenvolvimento de psicofármacos não levou diretamente à institucionalização desta centralidade farmacêutica (LAKOFF, 2005). Esta aproximação com a indústria farmacêutica resultados esforços para normalizar a prática profissional na psiquiatria e também é estimulada pelos esforços de marketing deste setor. A proposta é estudar a medicalização da infância pela ótica da Sociologia Econômica, concentrando a análise na relação dinâmica entre Estado e mercados. Esses novos processos vinculam sociedades a corpos, a subjetividades e afronteiras sempre variáveis entre a experiência do normal e do patológico(CAPONI, 2018; PETRYNA; LAKOFF; KLEINMAN, 2006). Conforme aponta Foucault (2018, p. 136), há uma [...] afrouxamento epistemológico constante o qual vai incluindo conjuntos de fenômenos que até então não tinham estatuto na ordem da doença mental". O tema da indústria farmacêutica global convida a um novo campo para a pesquisa em diferentes áreas e igualmente contempla a Sociologia Econômica. Propomos abordar a indústria farmacêutica enquanto campo com autonomia relativa e em interatuação com o campo da ciência e da saúde.

Conforme observam Bourdieu (2000, 2005);Zelizer (2011;[1985] 1994; Fligstein (2001a, 2001b) e Fourcade (2011) e Fourcade e Healy (2017), o mercado náo se constitui como livre jogo de forças abstratas entre oferta e demanda; é antes resultado de um arranjo social amplo que envolve agentes, instituiçóes em processos político-culturais complexos e passíveis de contestação. E esses processos constituem uma hierarquia moral dinâmica,a qual legitima a valoração e precificação de bens e pessoas; logo, estão em disputa os critérios de classificação da realidade. Qual a arquitetura e os pilares sobre os quais se constitui um novo mercado?

ParaFligstein (2001a, 2001b)e Bourdieu (2000, 2005), situaçôes de crise podem engendrar novos mercados como é o caso do mercado de informática nos EUA e o mercado de casas próprias na França.As mudanças que acompanharam a formação da Organização Mundial do Comér- 
cio (OMC) promoveram os padróes de qualidade e segurança. Conforme Fligstein e Mara-Dritta (1996), esses padróes permitem que produtos circulem fora dos Estados Nacionais respondendo a determinadas normas de qualidade e sem ameaçar a soberania nacional de padróes de fabricação dos respectivos países. Pesquisas anteriores analisaram os padróes de qualidade e segurança para alimentos, focando o mercado de produtos frescos e mercado de raçóes(MAZON, 2009; MAZON; MOURA, 2017). Tais estudos observam como esses padróes não são neutros e encerram disputas cognitivas e morais pela definição da qualidade, expressando interesses de atores poderosos.

Quando o assunto sãoos padróes em saúde mental ou diagnósticos de transtornos mentais a mesma década de 1980 marca um momento de virada. Falamos aqui de um manual - embora estadunidense - que se constituiu como referênciamundial na classificação das doenças mentais: o Manual Diagnóstico e Estatístico de Transtornos Mentais (DSM). Já existiam duas versôes anteriores; porém, na década de 1980, o DSM "antes um livrinho obscuro ao qual ninguém dava importância”, a partir do DSM-III se torna um gigantesco compêndio, "ícone cultural, best seller permanente e um objeto de culto: a bíblia da psiquiatria”. A partir de então, conta com vultosos investimentos e incentivos da indústria farmacêutica para os testes de novas drogas (FRANCES, 2016, p.12). O DSM é hoje o recurso mais disseminado para o diagnóstico de transtornos mentais (ROBERTS; LOUIE, 2017).

Conforme Petryna, Lakoff e Kleinman(2006), espera-se que o aumento da padronizaçãodo processo terapêutico - aqui falamos da padronização movimentada por um manual diagnóstico - promova o progresso científico da medicina, protegendo o público contra alegaçóes duvidosas sobre os efeitos e usos de substâncias reivindicadas como remédios para restaurar a saúde. Os padróes são importantes marcadores culturais e sociais da modernidade; porém, estão longe de serem neutros.Esta é a denúncia de uma parte dos estudiosos sobre saúde mental e saúde mental infantil: há um processo de inflação diagnóstica e relaçooes questionáveis entre a indústria farmacêutica e a psiquiatria (ARAÚJO, 2011) e este processo ganha corpo - entre outros com a intermediação do DSM(LAKOFF, 2002, 2006; FIRST; FRANCES, 2008; CAPONI, 2018, 2019; MARTINHAGO; CAPONI 2019; 
A padronização diagnóstica organiza vastas arenas burocráticas e divisões de trabalho envolvendo redes de especialistas, pesquisadores, informaçóes e espaços institucionais em todo o mundo (PETRYNA; LAKOFF; KLEINMAN, 2006). A depressão assim como o TDAHsão diagnósticos considerados como condição universal com prevalência transcultural consistente; tratamentos são anunciados como aplicáveis em todos os lugares. Essa suposta universalidade implica grande volume de confiança, sustentada pelo know-how especializado cujo produto final se torna um conjunto de documentos principais: diretrizes de vigilância que restringem a sintomatologia central a interpretaçôes bastante fixas como é o caso do DSM (LAKOFF, 2002). Esta confiança, no entanto, tem sido abalada e sofre revezes: a má administração científica, o tráfico de influência e, no caso de psiquiatras, o pagamento de viagens a congressos (WHITAKER, 2017). A influência da indústria farmacêutica na publicação de resultados em artigos científicos (HEALY, 2006) tem levado associações médicas a manifestaçóes públicas estabelecendo e esclarecendo limites éticos para a prática profissional, a exemplo do Conselho Federal de Medicina no Brasil (CFM, 2019; MAZON, 2019).

Distanciamo-nos, então, da perspectiva dos mercados como livre de jogo de forças entre atores racionais com preferências dadas e - nesta perspectiva da construção social dos mercados - interessa-nos focar amudança da ordem de questóes proposta por Ecks (2013), no lugar da ênfase econômica, a ênfase cultural do fenômeno: ao invés de interrogar quais drogas estão disponíveis no mercado para curar doenças, compreender antes como a presença das drogas e dos diagnósticos influencia a existência e a legitimação das doenças. Transpomos este raciocínio para pensar o ambiente propício para a legitimação dos transtornos da infância situando os critérios de classificação operados, em particular a partir doDSM-III. O episódio do TDAH marca um momento particular da história da psiquiatria nos EUA. Há uma mudança no ambiente das pesquisas médicas e uma alteração na modalidade de artigos demandados por revistas cientificas (LAKOFF, 2002). Esta tomada de posição cria o campo propício para a reemergência do TDAH que já tinha sido uma nosologia da década de 1930, período do higienismo, e fora deixada de lado na era da psicanálise. $\mathrm{O}$ artigo explora este momento e aborda a circulação dos psicotrópicos como parte da constituição da legitimidade da psiquiatria biomédica. 
O intuito deste artigo é explorar o contexto que promove uma reconversão tanto dos diagnósticos e manuais como no método de pesquisas publicadas na área da Psiquiatria infantil situando a reemergência do TDAH.O artigo está dividido em duas seçôes: na primeira,abordamos o referencial da Sociologia Econômica para pensar o mercado de fármacos; contexto de institucionalização dos psicotrópicos e a emergência do DSM a partir da PrimeiraGuerra Mundial e como necessidade militar e sua constituição como referência mundial a partir doDSM-III. Na segunda seção,abordamos aspectos da sociogênese da reemergência do TDAH e a tomada de posição dos cientistas na virada do tratamento psicodinâmico em direção à nova era das estatísticas e biologização dos transtornos mentais como momento de afirmação da psiquiatria infantil reforçada pela indústria farmacêutica.

\section{Padrões, mercados: a saúde e as categorias de classificação da realidade}

Bourdieu $(2000,2005)$, ao analisar a emergência do mercado de casas próprias, mostra como o Estado preenchido por atores recém-saídos na escola de Chicago e mobilizando estudos econométricos e estatísticos - opacos para seus colegas antigos burocratas e que náo dominavam a técnica - promovem uma reconversão de ideias. A partir desse processo,o estímulo, tanto do lado da demanda como do lado da oferta,cria o ambiente para o mercado de casas próprias: a necessidade de ter uma casa surge como um arbitrário cultural. O destaque de Bourdieu é para a tomada de posição dosjovens burocratas que contribuíam para revolucionar o Estado e, assim, criar um item de mercado que até então não existia e que iluminou a construção tanto do Estado como do mercado enquanto processos instituídos em interatuaçáo - nem atores racionais a fim, nem o movimento inexorável das forças econômicas - antes relaçôes de interinfluência nas quais motivaçôes, interesses e expectativas são criados e transformados no curso da própria ação (BOURDIEU, 2000, 2005).Igualmente, quando falamos da reemergência do TDAH ou da revolução psicodiagnóstica mais ampla,é consenso entre autores que a biologização da abordagem diagnóstica constitui-se em sacrifício 
do procedimento psicodinâmico anterior ao mesmo tempo em que há um deslocamento do foco dos estudos de caso individuais para a nova era das estatísticas; movimento promovido pela tomada de posiçáo de agentes privilegiados(LAKOFF, 2000, 2005, 2006; LIEBERMAN; OGAS, 2019; CAPONI, 2019;MARTINHAGO; CAPONI, 2019). É possível constatar uma revolução nos critérios de classificação da realidade, não da patologia em si, mas, na forma de abordagem do que pode ser considerado um dado de pesquisa como indicador de uma patologia; nas palavras de Foucault (2018), um afrouxamento epistemológico dos critérios diagnósticos. Qual o ambiente cognitivo promotor deste deslocamento? Para falar dele, situamos a seguir aspectos da construção de padróes diagnósticos em saúde mental a partir da era do DSM e suas revisóes.

\section{$2.2 \mathrm{O}$ contexto de emergência dos padrões diagnósticos na psiquiatria e a construção social da doença mental}

Quando o assunto é o mercado em torno da saúde, características particulares dos bens de consumo da saúde devem ser destacadas. Diferentemente de outros bens acessíveis nas prateleiras de supermercados ou em lojas, os medicamentos assumem duas particularidades fundamentais: é necessária a prescrição e o receituário; deste modo, somente podem ser consumidos após e através de uma autorização médica expressa pelo receituário. Igualmente, trata-se de bem credencial - a qualidade não é verificável antes (roupas, celulares) ou durante (viagens) a experiência de consumo; somente depois e diante da opinião de profissional autorizado que possa atestar (FIUZA; LISBOA, 2001; LAKOFF, 2006; MAZON, 2019). Portanto, observar a forma como medicamentos psicotrópicos operam em variadas situaçóes clínicas aponta para os efeitos ambíguos dessas intervençóes.

Os efeitos que um determinado medicamento produz - antes do que efeitos sobre pacientes - são igualmente efeitos de discurso e que dependem, pelo menos em parte, do ambiente (CAPONI, 2019; LAKOFF, 2005) e das relaçóes de interinfluência com outros campos (MAZON, 2019). Nesse sentido, essas drogas são instrumentos cuja função é moldada pela forma de racionalidade em que se constituem e a partir dos efeitos dos discursos que as colocam em circulação; são os meios para 
vários fins possíveis (MAZON, 2019; LAKOFF, 2000). A identificação de seus diversos usos e significados fornece pistas para compreender singularidades nos regimes de saúde e formas de gestáo da saúde. Como veremos com a clorpromazina (antiestamínico, antivomitivo, psicotrópico) e com o metilfenidato e o TDAH, a conquista da "especificidade" do psicotrópico requer a adoção de um conjunto de conceitos e técnicas que reconfiguram o objeto do conhecimento especializado e a autoconcepçáo do especialista (LAKOFF, 2005).

\subsection{A guerra, os padrões e os manuais - efeitos do discurso}

Pinel é o nome conhecido como o pai da psiquiatria e sua ação é considerada revolucionária por libertar os doentes mentais de suas correntes. Segundo Frances (2016) ele realizou um feito ainda maior: jogou fora a superstição medieval que considerava doenças mentais possessões demoníacas (e que suas vítimas deviam ser punidas ou,às vezes, queimadas) e afirmou a "enfermidade mental como mal com causas naturais equivalentes às da doença médica” (FRANCES, 2016, p.82). Igualmente Pinel desenvolveu um modelo de asilo dedicado às necessidades dos doentes mentais, onde essas pessoas seriam tratadas dignamente em ambiente agradável e seguro. Esse modelo de asilo se espraia por toda a Europa e EUA (FRANCES, 2016, p. 83).

No campo científico, Pinel reuniu a análise de síndromes de Syndeham aos métodos classificatórios de Lineu: então, os rótulos diagnósticos na psiquiatria estariam referenciados pela ciência natural. Os primeiros sistemas de classificação eram franceses;porém, o foco gradualmente se deslocou para a Alemanha onde Emil Kraepelin, irmão de um grande naturalista, aprimorou suas habilidades observacionais. Ao mesmo tempo em que estabeleceu as bases classificatórias, Kraepelin manteve a ambição dos higienistas do século XIX de incluir os problemas sociais na linguagem médica; ele mobilizou o recurso da estatística, diagnóstico com base na herança ou degeneração hereditária bem como o recurso da localização anatomopatológica de lesóes cerebrais ${ }^{3}$ (CAPONI, 2010, p. 476). No entanto, Kraeplin

3 Kraepelin criou um novo espaço discursivo para falar da enfermidade mental, o qual inclui novas nosologias, novas metodologias de investigação para falar dos doentes, da família e dos descendentes (CAPONI, 20I0, p. 478). 
era médico hospitalar com nenhum conhecimento de ambulatório. Sua concepção de psiquiatria era formada por pacientes em confinamento e sua classificação teria pouco a dizer dos pacientes diagnosticados atualmente (FRANCES, 2016, p. 84). Conforme Frances, Freud será o responsável por preencher esta lacuna, "ele fará pelos pacientes externos aquilo que Kraeplin fez pelos internos" (FRANCES, 2016, p. 85). E Freudé o nome que vai inaugurar a psiquiatria ambulatorial dando a ela nova forma de classificar os pacientes; propondo a psicanálise, ele reconceituou a neurose como derivada de conflito psicológico (LOPES, 2001) 4

Os primeiros psiquiatras eram poucos e trabalhavam em asilos. Depois de Freud, a especialidade psiquiátrica mudou o foco dos pacientes internos para pacientes externos "não tão doentes", conforme esclarece Frances (2016, p. 86). Se Frances identifica um movimento de especialização da psiquiatria situando a saída de psiquiatras dos hospitais rumo aos consultórios parao atendimento embasado na técnica da associação livre freudiana, Caponi (2019) e Lakoff (2005) relativizam essa narrativa apontando a chegada da clorpromazina - algumas décadas mais tarde, nos anos 1950- observando que a saída mais importante dos hospitais será a dos pacientes a partir dos relatos triunfantes dos psiquiatras a respeito dos efeitos desta droga ${ }^{5}$. Nessa época, as guerras mundiais também ampliaram as fronteiras da psiquiatria e colocaram-na no centro das atençóes. A enfermidade psiquiátrica foi identificada como ameaça ao esforço de guerra e apontada como causa frequente de inaptidão para o serviço militar, forma comum de baixa e fonte de incapacitação (FRANCES, 2016, p. 86;LIEBERMAN; OGAS, 2019). Segundo Frances, as classificaçóes existentes nos hospitais não eram suficientes para diagnosticar o que afligia as tropas; aqui é possível observar mais uma vez que o foco não é a doença,an-

4 Mais informações sobre os conceitos freudianos, publicações, vida e obra de Freud, ver Gay (1989).

5 Considerada como bala mágica da psicose a descoberta da clorpromazina em 1952 foi responsável pela revolução psicofarmacológica relatada de maneira triunfalista pelos psiquiatras e associada à promessa de eliminação de técnicas de contenção e eletrochoque assim como os pacientes poderiam ser tratados em casa. A descoberta da clorpromazina inaugura um modelo de descoberta, validação e divulgação de novos medicamentos psicotrópicos (CAPONI, 2019). Em 1957, o primeiro antidepressivo tricíclico foi desenvolvido, o que acabaria por contribuir para um aumento radical no diagnóstico da depressão. No contexto transnacional de hospitais psiquiátricos superlotados e na crítica generalizada das instituições psiquiátricas, esses medicamentos -especialmente os antipsicóticos -foram a resposta para várias necessidades e seu uso se espalhou rapidamente (LAKOFF, 2005). 
tes, o comportamento desejado. Psiquiatras foram convocados para refinar os sistemas declassificação (POLS; OAK, 2007; LIEBERMAN; OGAS, 2019, p. 240). Uma nova classificação diagnóstica foi criada pelo Exército, revisada pela Administração de Veteranos e revisada mais uma vez pela Associação Americana de Psiquiatria, o Manual Diagnóstico Estatístico I, o primeiro DSM publicado em 1952. Tanto o DSM I como II não eram ainda uma referência, não eram "lidos, nem utilizados" (FRANCES, 2016, p. 87).

É desse momento a institucionalização da psicofarmacologia. Entre os anos de 1952 e 1954,surgiu a clorpromazina; considerada o primeiro fármaco eficaz para o tratamento da psicose (CAPONI, 2019, p. 22) ${ }^{6}$. É interessante observar que a disseminação da clorpromazina será inicialmente como anti-histamínica e anestésica(na marinha francesa e, posteriormente, nos Estados Unidos produzida pela Smith, Kline and French). Nos EUA, ela era vendida como antivomitivo, anti-histamínico e apenas posteriormente como antipsicótico e aplicada massivamente no Pilgrim State Hospital em Nova York. Uma vultosa campanha publicitária anuncia os resultados da droga: desinteresse e bom comportamento dos pacientes, considerada uma lobotomia química (CAPONI, 2019).

O início dos anos 1970 será o começo de uma mudança de rumo para os critérios de classificação diagnóstica em saúde mental. Dois artigos publicados e amplamente divulgados questionam a validade universal das classificaçóes diagnósticas em saúde mental. $\mathrm{O}$ primeiro, um estudo internacional britânico-estadunidense que aponta como psiquiatras dos dois lados do oceano tiravam conclusóes diagnósticas radicalmente diferentes, embora avaliando os mesmos pacientes (FRANCES, 2016, p. 87; LAKOFF, 2005). No segundo artigo, um psicólogo mostrou como era fácil induzir psiquiatras a fornecer não apenas diagnósticos, mas, também, tratamentos inadequados ${ }^{7}$.

É nesse momento que surge Robert Spitzer;segundo Frances (2016, p. 88), o homem que veio para "salvar a psiquiatria" (é interessante

6 Detalhes sobre a institucionalização da psicofarmacologia, surgimento e difusão da clorpormazina ver Caponi, 2019.

7 Alunos de pós-graduação orientados por este psicólogo foram até unidades de emergência alegando ouvir vozes; todos foram internados em hospitais psiquiátricos apesar de mais tarde se portarem de modo perfeitamente normal (FRANCES, 2016, p. 87). 
observar como relatos triunfantes são constantes na narrativa da psiquiatria). Spitzer embarcou numa missão por tornar o diagnóstico sistemático e confiável; ele tinha como objetivo, segundo Frances, contornar as fragilidades dos critérios de classificação diagnóstica em dois procedimentos: criação de listas de checagem dos critérios diagnósticos de pesquisa e desenvolvimento de instrumentos de entrevista semiestruturada para controlar inconstâncias da avaliação. Interessante notar é como Frances avalia as consequências deste método considerado como confiável: ele permitiria que a pesquisa psiquiátrica empregasse as ferramentas - para ele "incríveis" e que até hoje não se demonstrou a relação delas com as doenças psiquiátricas (WHITAKER, 2017; CAPONI, 2019, 2014; MARTINHAGO, et al. 2019) - da biologia molecular, da genética, da estatística multivariada e dos ensaios controlados com placebo (FRANCES, 2016, p. 88).

O objetivo de Spitzer era delimitar um conjunto de regras para a negociação de futuros padróes. Neste tema, Spitzer e seus colegas reformadores foram bem-sucedidos, pois o DSM nesta versão e nas posteriores conquistou legitimidade. Conforme Lakoff (2005), a utilização deste sistema de listas de checagem e instrumentos de entrevistas para gerar e refinar padróes pode ser entendida como um processo de normalizaçáo profissional. Conforme Ewald (1990, p. 148) observa:“[...] a normalização não produz objetos, mas procedimentos que levarão a um consenso geral sobre a escolha de normas e padróes”. Os procedimentos normativos - neste caso, o desenvolvimento de novas formas de definir e regular a doença - náo apenas restringiram, igualmente criaram novos objetos de conhecimento e formas de identidade.

Lakoff (2005) esclarece que o entendimento de como os psicofármacos operam na psique é surpreendentemente diferente da premissa da psiquiatria biomédica, na qual a medicação atinge uma deficiência neuroquímica específica para corrigir uma doença cerebral. Como, então, a psiquiatria adotou a lógica da especificidade?

O fenômeno envolve dois processos interligados: por um lado, a regulamentação governamental exigia que os produtos farmacêuticos provassem ter efeitos direcionados para circular no sistema biomédico; por outro lado, para demonstrar tais efeitos, os pesquisadores precisavam ser capazes de classificar o distúrbio de maneira padronizada. Assim, tanto a intervenção quanto a doença tiveram que ser reconfiguradas para alcançar especificidade. (LAKOFF, 2005, p. 18). 
Em 1962, o Congresso dos EUA alterou a legislação da FDA para exigir que todos os novos medicamentos fossem testados quanto à segurança e eficácia, de acordo com estudos randomizados e controlados por placebo:

Esse foi um evento importante na transformação de psicofármacos em agentes com efeitos específicos. Para que os medicamentos se mostrassem eficazes de acordo com critérios biomédicos, eles precisavam visar doenças claramente definidas. Para operar dentro do sistema regulamentado de biomedicina, os medicamentos tiveram que incorporar o modelo do sistema de relação entre doença e intervenção. De acordo com esse modelo, as doenças são entendidas como entidades estáveis que existem fora de sua modalidade em indivíduos específicos, o que pode ser explicado em termos de mecanismos causais específicos localizados no corpo do paciente. (LAKOFF, 2005, p. 20).

Sob a nova legislação da FDA, o que permitiria que drogas fossem comercializadas e prescritas pelos médicos seria a garantia de que as intervençôes químicas que elas engendram pudessem ser mensuráveis em termos de eficácia em populaçóes de pacientes comparáveis. Os pesquisadores de psicofarmacologia clínica, portanto, precisavam de grupos de pacientes homogêneos para o teste de novas substâncias. No entanto, a prática diagnóstica não era notoriamente confiável entre os observadores clínicos: o que um psiquiatra observa nos sintomas de um paciente pode ser entendido de maneira bastante diferente por outro. Isso dificultou os esforços para medir a eficácia das intervençóes: sem prática diagnóstica consistente, não havia como garantir que os estudos clínicos fossem aplicados ao mesmo tipo de paciente. Em resposta à necessidade de populações de pacientes homogêneas para a pesquisa, os pesquisadores da psiquiatria clínica projetaram escalas e questionários de classificação que codificariam as doenças ao longo do modelo de especificidade - como entidades discretas que correspondiam a intervençóes terapêuticas direcionadas. Foram criados, então, os Critérios Diagnósticos de Pesquisa (CDP, RDC na língua inglesa). Um dos principais objetivos desses critérios era garantir a seleção de grupos de indivíduos homogêneos que atendessem a critérios diagnósticos específicos.

Uma vez que a regulamentação dos produtos farmacêuticos exigia acordo com as diretrizes de ensaios clínicos randomizados, o desenvolvimento de padróes de diagnóstico tornou-se necessário. Esse processo de padronização foi inicialmente importante para fins de pesquisa e não na clínica. As clínicas nos Estados Unidos - a maioria trabalhando de acordo com modelos psicodinâmicos individualizados - podiam ignorar esses 
critérios de diagnóstico e escalas de classificação. Os escândalos citados por Frances (2016) com relação à falta de entendimento no padrão diagnóstico entre psiquiatras exigiam providências. Tais pressões, bem como o desejo de melhorar o status da psiquiatria na medicina, levaram a Associaçáo Americana de Psiquiatria (APA) a estabelecer limites à autonomia interpretativa de seus membros.

Os procedimentos de diagnóstico foram o foco inicial desse esforço. O acordo de 1980 da APA sobre uma nova edição do Manual Diagnóstico e Estatístico de Transtornos Mentais (DSM) estabeleceu um conjunto de padrôes que regulam o diagnóstico de acordo com o modelo de especificidade da doença. Neste momento, Spitzer foi nomeado para chefiar o comitê diretor do DSM-III e ganhou liberdade para escolher equipe e procedimentos de trabalho, como já mencionado. Spitzer - que foi um dos autores dos Critérios de Diagnóstico da Pesquisa (CDP) - buscou teóricos com ideias semelhantes que embasavam o diagnóstico em traços puramente descritivos ou "fenomenológicos", em vez de usar explicaçôes teóricas, como etiologia psicodinâmica, como base para classificação. Conforme Frances (2016, p. 90) a escolha de Sptizer foi por um grupo de psiquiatras - e alguns psicólogos - da emergente e coesa legião de pesquisadores de visão "biológica".

Segundo Lakoff (2005, p. 22):

Um processo de ajuste mútuo entre droga e diagnóstico, intervenção e doença gerou novas definições de patologia e, portanto, de normalidade também. O DSM-III foi estendido para novos nichos devido à sua capacidade de tornar a patologia comportamental reconhecível entre domínios profissionais.

Seus padrões têm vários usos possíveis: na coleta de dados epidemiológicos, no desenvolvimento de algoritmos de tratamento e na reivindicação de benefícios de seguro (LAKOFF, 2005). Desse momento em diante, a psiquiatria conquista espaço de reconhecimento na medicina - torna-se“menina dos olhos, não mais filha bastarda” (FRANCES, 2016, p. 87). O orçamento do Instituto Nacional de Saúde Mental cresceu; na maioria das faculdades de medicina a psiquiatria, chegou ao segundo lugar entre as fontes de recurso para pesquisa. Igualmente a indústria farmacêutica 
investe fartamente"na corrida para o desenvolvimento de novos medicamentos psiquiátricos lucrativos” (FRANCES, 2016, p. 88).

Daí em diante, o DSM alça a legitimidade que mantém nos dias atuais; vendendo centenas de milhares de cópias - quantidade maior que a de profissionais da saúde mental - ele foi recebido como autoridade por clínicos, professores, alunos, pesquisadores, companhias de seguro, sistemas educacionais, tribunais (FRANCES, 2016, p. 93). Frances reconhece que a inflação diagnóstica foi uma consequência do DSM-III. Houve uma promoção da doença influenciada pelos fabricantes de remédios (FRANCES, 2016). Deve-se observar como esta clara aproximação com a indústria farmacêutica ganha tons mais fortes na publicação do DSM-IIIR - revisão do DSM-III(pequena revisão com a finalidade de corrigir erros e omissóes do DSM-III) - e publicada sete anos depois, em 1987.

Com a aprovação do DSM-III, a APA anunciou a morte da clínica psicanalítica na profissão psiquiátrica estadunidense. Se na psiquiatria dinâmica das décadas de 1950 e 1960, o conhecimento havia sido acumulado e os diagnósticos apresentados por meio de exemplo e analogia (eram suas proezas exegéticas a prova de confiabilidade), agora, o psiquiatra, usando o DSM-III, tornou-se mais um medidor do que um intérprete:

Diferentemente do caso individual, a população diagnosticada não tinha histórico particular, história de relacionamento com os pais ou rejeições na escola - seus membros compartilhavam um conjunto de respostas para as perguntas dadas, e essas respostas os encaixavam juntos em uma categoria de doença. Como regime de padrões, o DSM-III procurou produzir resultados funcionalmente comparáveis em domínios diferentes. Seu objetivo principal era a confiabilidade: se a mesma pessoa fosse a duas clínicas diferentes, ele ou ela deveria receber o mesmo diagnóstico em cada local. Baseados em características diretamente observáveis e ostensivamente ateóricas, os novos padrões de diagnóstico estruturaram um sistema mais amplo de comunicação. Enquanto a epistemologia subjacente ao novo manual era positivista - existiam distúrbios no mundo a serem descobertos - suas categorias eram afiadas de acordo com princípios pragmáticos: o patológico poderia ser melhor [sic] definido pelo disfuncional. (LAKOFF, 2005, p. 12).

As escalas de classificação baseadas em questionários foram refinadas para medir normas de funcionalidade, possibilitando que diferentes observadores usassem o mesmo critério na avaliação diagnóstica. Embora o manual 
tenha professado suspender a questão da etiologia, seu desenvolvimento teve como premissa a esperança de que os correlatos orgânicos acabassem por corresponder a categorias de doenças bem definidas. O DSM-III era um sistema padronizador, mas também dinâmico: suas categorias estavam evoluindo, não permaneciam fixas, e seus autores criaram uma estrutura baseada em comitês dentro da profissão para testar e revisar definições.

\section{Reemergência do TDAH e a era da estatística}

Para falar da origem do TDAH, Lakoff (2000, p. 50) cita o trabalho científico de George Still, médico do Hospital King's College no início do século XX. "Still fez fama ao observar como certas patologias infantis (relacionadas ao controle moral) poderiam ser explicadas por causas orgânicas. Ele nomeava o fenômeno como defeitos de voliçáo inibitória" (LAKOFF, 2000, p. 50). Crianças incapazes de permanecer paradas e que também tinham outros defeitos: roubar, mentir, comportamento violento, comportamento sexual inadequado.

Para Still, a inibição volitiva era o fundamento do comportamento civilizado e pré-requisito para tornar um adulto moral. A ausência desta inibiçáo seria uma falha correlacionada com outros estigmas da degeneração como características frenológicas anômalas ${ }^{8}$ (LAKOFF, 2000, p. 150). As ideias de Still são comuns deste período e não explicam porque ele se tornou conhecido nos dias de hoje. Segundo Lakoff (2000, p.151), o que o resgata da obscuridade é sua observação como característica marcante destas crianças a incapacidade de atenção sustentada e a incapacidade de concentração; pilares do TDAH atual.

A ciência social baseada na evolução perdeu fôlego assim como relação entre atenção, vontade e comportamento moral deixou de ser um grande problema. Setenta anos depois de Still, na década de 1990, o TDAH foi recentemente retomado. Enquanto os casos de Still eram raros, o momento atual é de um surto de TDAH. Estima-se que este transtorno corresponda nos dias atuais a 5\% da população escolar (LAKOFF, 2000, p. 153).

8 Ele se dedicava particularmente a medida com fita métrica da circunferência do crânio destas crianças assim como estudava o grau de degeneração dos antepassados (LAKOFF, 2000, p. 150). 
No Brasil, estima-se que 4,4\% de crianças e adolescentes entre 4 e 18 anos tenham déficit de atenção conforme dados do primeiro estudo epidemiológico do Instituto Glia (VEJA, 2011). O distúrbio foi definido como uma síndrome comportamental caracterizada por impulsividade, perturbação e dificuldade em manter a atenção vigilante.

\section{I A nova era da Psiquiatria Infantil e os transtornos da infância: os prescritores e sua tomada de posição}

Conforme Lakoff (2000), devido ao status instável da síndrome, descoberta náo seria um termo apropriado para descrever o ressurgimento do déficit de atenção. Para compreender a legitimidade do distúrbio e seu impulso na década de 1990, é preciso fazer apelo ao conceito de direitos individuais, risco social e personalidade e como eles se entrelaçaram para dar concretude ao distúrbio.

Lakoff propóe situar historicamente a psiquiatria infantil como forma de mapear o terreno sugerindo como o distúrbio coincide com o rejuvenescimento da psiquiatria infantil como disciplina. A especialidade da psiquiatria infantil surgiu de uma combinação de grupos que, a partir do final do século XIX,se organizaram em torno do problema do ajuste social.Os reformadores progressistas codificaram a distinção entre infância e idade adulta e estimularam os governos a manter um interesse protetor no desenvolvimento moral dos futuros cidadãos (ARIÈS, [1981] 2011; ZELIZER, [1985] 1994). Durante a década de 1920, os movimentos de higiene mental e orientação infantil se reuniram em clínicas de filantropia nas quais assistentes sociais, professores e médicos poderiam obter referências em questóes de saúde juvenil (). As patologias do desenvolvimento mental tornaram-se objeto de escrutínio nos anos 1930na Johns Hopkins, onde Leo Kanner ([1972] 2000) foi um dos primeiros psiquiatras infantis acadêmicos:

Kanner promoveu a abordagem dinâmica da personalidade adotada por seu mentor, Adolph Meyer, cuja perspectiva teórica permaneceria dominante na disciplina nos anos 70. Esse grupo explorava aspectos biográficos passadoscomo origem possível dos problemas presentes.A doença mental deveria ser vista como o ápice de dificuldades pessoais. Embora Meyer duvidasse de uma ênfase na sexualidade infantil e na repressão na etiologia da psicopatologia, ele compartilhou com os psicanalistas uma crença no papel central da história de vida na explicação da doença mental. Por esse motivo, a pesquisa decorrente desta tradição centrou-se no estudo de caso. (apud LAKOFF, 2000, p.158). 
No seu guia publicado em 1957 sobre prática clínica na psiquiatria infantil, Kanner questiona a antiga abordagem considerada ultrapassada do diagnóstico que, para ele,foi adequadamente substituída pela técnica de história de vida: "quem era o paciente parecia menos importante do que o que ele tinha” - esta antiga psiquiatria era considerada estática, descritiva e nosográfica (KANNER, 1957 apud LACKOFF, 2000, p. 158). Descritiva e nosográfica são expressóes mobilizadas por Kraeplin no seu sistema de diagnóstico mencionado na seção anterior. Estes termos retornam na era da psiquiatria biomédica recente. Lakoff (2000, p. 152) cita que o ressurgimento da nosologia descritiva em psiquiatria infantil guarda coincidência temporal com a reemergência do Transtorno do Déficit de Atenção (TDA) como pode ser observado em artigos do periódico Journal of the American Academy of Child Psychiatry, analisado por Lakoff (2000, p. 154):

Em 1959, quando as profissionais da psiquiatria infantil se fundiram em um grupo poderoso o suficiente para obter reconhecimento profissional, a psiquiatria como um todo estava sob o domínio do modelo neofreudiano. Assim, os primeiros anos do Journal of the American Academy of Child Psychiatry (fundada em 1962), tinham um sabor analítico distinto. Ao discutir problemas comportamentais que variam de roer unhas a suicídio, os escritores da revista procuravam com mais frequência as experiências da primeira infância em busca de pistas etiológicas. Os artigos tenderam a apresentar estudos de caso e não análises estatísticas de grupos de pacientes que posteriormente apareceriam. Mães superprotetoras, apontadas como responsáveis por uma variedade de patologias da Guerra Fria, eram casos frequentemente citados na revista.

Os processos do egoforam banidos nas décadas seguintes e substituídos pela apresentação de estatísticas, gráficos e estudos longitudinais (LAKOFF, 2000, 2005). Ao invés da mobilização de teóricos fundadores consagrados, as referências da psiquiatria passaram a ser estudos estatísticos. Esse novo ambiente refletiu alianças disciplinares em mudança na psiquiatria infantil; ao invés da proximidade com educação e bem-estar social, os líderes de opiniáo do campo optaram por uma aproximaçáo aos campos de especialidade com maior prestígio científico: neuropsicologia, biologia e epidemiologia (LAKOFF, 2000, p. 155).

Conforme Lakoff (2002) observa, a mudança se inicia a partir das editorias dos periódicos deste setor. Este autor analisa a trajetória de líderes de opinião, conforme Bourdieu (2000, 2005, 2009), os prescritores,que farão 
uma reconversão cognitiva no campo científico. No âmbito da pesquisa em psiquiatria infantil, o destino dos modelos dinâmicos foi selado em 1976, quando Melvin Lewis assumiu o cargo de editor do Journal of the American Academy of Child Psychiatry. Desde o início, o periódico era dirigido pelo teórico dinâmico Rexford. Lewis abriu o periódico às ciências biológicas e solicitava dos pesquisadores definiçóes padrão que pudessem ser replicáveis de acordo com métodos científicos. $\mathrm{O}$ formato dos artigos mudou, indicando uma transformação no que constituía conhecimento médico razoável nesta área de estudos. Esta nova forma colocava em cheque o estudo de caso individual. Dali em diante, a validade científica exigia testes em populaçóes claramente definidas.

Outro nome de destaque do período é o de Stella Chess. Ela fazia pesquisas junto com seu marido Thomas Alexander; segundo Lakoff (2000, p.155), eles são considerados anunciadores da virada somática na área do desenvolvimento infantil. O casal apresentou os resultados de estudos longitudinais - The New York Longitudinal Study - desenvolvidos desde a década de 1950 e indicando que alguns "estilos comportamentais" eram contínuos desde a infância e pouco afetados por fatores ambientais (WHITE, 2020). Este foi um golpe duro na teoria psicanalítica, baseada em estudos de caso. Conforme observa Lakoff (2000, p. 154), os estudos de Chess e Alexander absolviam os pais da culpa pelos problemas na personalidade dos filhos. Ao apontar a existência de estilos comportamentais inatos, eles proporcionavam alívio para a relação entre pais e filhos e, ao mesmo tempo,convidavam os pais ao ajuste de suas expectativas às características inerentes dos filhos: desmame, treinamento no banheiro, disciplina e a socialização.

\subsection{O DSM e o TDAH: as afinidades eletivas}

Voltando ao DSM-III, o Comitê de Distúrbios Infantis desta versão do manual diagnóstico, nomeado por Spitzer, incluiu vários defensores de modelos genéticos. Especialistas que já contavam com pesquisas sobre hiperatividade. Lakoff (2000) cita o nome de Stella Chess - mencionada acima - autora que, num artigo de 1960, empenha-se em retirar a carga de culpa dos pais (como mencionado) pela hiperatividade, defendendo o comportamento infantil como condição temperamental. 
A hiperatividade estava surgindo como um distúrbio fundamental na psiquiatria infantil. Dado o número de membros que investiram no problema, é intrigante queo comitê propôs em 1980 um novo nome para hiperatividade. O Distúrbio do Déficit de Atenção foi rebatizadocom baseno trabalho da psicóloga Virginia Douglas.

A partir de observações e experimentos com crianças diagnosticadas com hipercinesia do DSM-II, Douglas havia mostrado alguns anos antes que os problemas motores não eram, de fato, a característica marcante de sua desordem (Douglas, 1972). Depois de administrar baterias de questionários, observações e testes assistidos por máquina, ela descobriu que os principais problemas eram a incapacidade de "parar, olhar e ouvir". Eles não conseguiam dedicar atenção a uma tarefa específica por períodos prolongados. Douglas enfatizou que essa incapacidade de inibir impulsos perturbadores não era apenas um excesso de movimento, mas deveria ser considerada uma desordem da vontade. (LAKOFF, 2000, p. 160).

Em seu artigo seminal que introduz a noção de déficit de atenção, Douglas citou William James como uma fonte autorizada para reunir as faculdades de atenção e vontade. Para Lakoff (2000), essa referência era semelhante à passagem que George Still havia citado 70 anos antes quandomencionou James e a desordem da vontade.

Com o artigo de Douglas,surgiu a história oficial do distúrbio, legitimando-o como uma entidade oficialmente aceita. O Comitê de Distúrbios Infantis do DSM acatou a redefinição de Douglas e, assim, expandiu o alcance do distúrbio, pois uma criança pode ser diagnosticada com déficit de atençáo sem ser hiperativa. As características essenciais, de acordo com o DSM-III, eram "sinais de desatenção e impulsividade inadequadas" e possivelmente hiperatividade.

O principal terreno futuro do transtorno foi destacado: "Na sala de aula, dificuldades de atenção e impulsividade são evidenciadas pelo fato de a criança não permanecer em uma tarefa por muito tempo e ter dificuldade na organização e na conclusão do trabalho"(AMERICAN PSYCHIATRIC ASSOCIATION, 1980 apud LAKOFF, 2000, p. 161).

Como a escola foi o local onde o distúrbio apareceu, professores - em colaboração com os pais e psicólogos escolares- tornaram-se a primeira linha de defesa. A psiquiatria de caráter somático na esteira do DSM-III não envolveu necessariamente a conversão de distúrbios previamente concebidos em etiologias baseadas no cérebro (como na esquizofrenia e depressão). 
Ao invés disto, o transtorno de déficit de atenção segue uma rota diferente: a expansão de uma doença já orgânica (hipercinesia ou disfunção cerebral mínima) para cobrir uma variedade mais ampla de casos.

No DSM-III, os critérios para cada subcategoria de transtorno de déficit de atenção - desatenção, impulsividade e hiperatividade - foram listados separadamente. Para diagnosticar a condição, o manual exigia que os avaliadores dessem respostas afirmativas sobre dois ou três dos possíveis sintomas em cada subcategoria. (LAKOFF, 2000, p. 162).

Surgiram novas escalas projetadas para a avaliação de crianças por pais ou professores. Um elemento-chave na padronização de avaliações foi a aprovação da Escala de Connors, a mais importante de uma série de escalas para classificação de observação de comportamento. Essa escala foi publicada pela primeira vez como um guia para pesquisa clínica de medicamentos e somente num momento posterior constituiu o aparato diagnóstico geral (CONNORS, 1969 apud LAKOFF, 2000, p. 162).

A partir desse momento, houve um rápido aumento no uso de medicação para hiperatividade e o avanço nos investimentos de tecnologia para detecção de hiperatividade: desde os primeiros testes da década de 1960, em que os pesquisadores colocavam uma fita no chão e contavam o numero de vezes que a criança passa por ela num determinado período de tempo da brincadeira até década de 1990 quando já haviadispositivos eletrônicos como pedômetro (acessório para o ombro que mede quantitativamente os movimentos), entre outros. O crescente interesse no distúrbio entre os pesquisadores após a publicação do DSM-III pode ser mapeado em termos do número relativo de artigos publicados: se eram somente três entre 1971 e 1977 na revista Academy em 1984, quando uma edição inteira foi dedicada ao transtorno de déficit de atenção, de 10 a 20 artigos eram publicados todos os anos nas páginas dessarevista. A prática clínica tornou-se cada vez mais focada no distúrbio:

Embora tenha sido declarada "em crise" menos de dez anos antes, a psiquiatria infantil estava em boa forma no final dos anos 1980. Em um discurso na reunião anual da Associação de Psiquiatria Infantil, Stella Chess anunciou que a disciplina havia finalmente "chegado à maturidade". Como no resto da psiquiatria, a nova vitalidade do campo estava ligada à conversão dos médicos para um modelo clinicamente viável de diagnóstico e tratamento. (LAKOFF, 2000, p. 162). 


\section{Considerações finais}

O artigo propôs situar o momento de mudança - tanto nos artigos como nos procedimentos de pesquisa - que marca o DSM-III enquanto forma de abordagem dos transtornos psiquiátricos situando a indústria farmacêutica na conformaçáo de novos discursos. Este é o momento da reemergência do TDAH e marca o confronto com a abordagem psicodinâmica freudiana que será secundada pela alternativa de testes e procedimentos estatísticos. Para situar o contexto destas transformaçóes, mobilizamos autores da Sociologia Econômica a partir da idéia do mercado de medicamentos enquanto campo de lutas - luta em torno dos critérios de classificação da realidade - bem como a dinâmica de interatuaçáo com o campo da saúde.

Autores da Sociologia Econômica apontam como os períodos de crise e guerras podem fazer com que novas instituições apareçam. Neste artigo, foi possível observar como o momento e a circunstância daPrimeira Guerra Mundial marcaram o início das classificaçóes diagnósticas em saúde mental como necessidade militar com foco no comportamento desejado dos soldados;estas classificaçóes estão na origem do DSM, manual de referência mundial para transtornos mentais.

A atuação dos profissionais da psiquiatria expressa de maneira clara o caráter de bem credencial dos psicotrópicos: o médico atesta quais resultados devem ser esperados e isso náo depende da experiência dos pacientes. A singularidade da psiquiatria com relaçáo à dinâmica de descoberta das drogas é particularmente diversa. A psiquiatria inverte a ordem da descoberta: uma droga é disponibilizada no mercado como anti-histamínico ou remédio para vômito e finalmente ela se transforma em psicotrópico, como é o caso da clorpromazina, e seu efeito anunciado é no sentido da normalização de comportamentos (FOUCAULT, 2018). Há um deslocamento do significado do que se espera do efeito da droga: náo a cura da doença, apenas a mudança de comportamento com a finalidade de controle, expressão do biopoder. Se a descoberta da clorpromazina inaugura um modelo de descoberta, validação e divulgação de novos medicamentos psicotrópicos (CAPONI, 2019), a reemergência do TDAH reforça este modelo - o efeito da droga não tem ambição de cura, mas de controle de comportamento socialmente indesejado. 
Se Bourdieu (2000) observa novos atores a ocupar o espaço do Estado na constituição do mercado de casas próprias na França assim como o efeito prescritor do discurso destes atores a partir de novas ferramentas econométricas igualmente Lakoff (2000) sugere a presença de novos prescritores nos editoriais de periódicos de prestígio da Psiquiatria Infantil nos EUA os quais dão suporte aos pesquisadores afeitos ao modelo biomédico que, ao questionar os métodos da psicanálise, inauguram a nova era da estatística e dos modelos biológicos no momento do ressurgimento do TDAH.

Os efeitos atribuídos à medicação psicotrópica na psiquiatria biomédica contemporânea não estão embutidos na medicação (LAKOFF, 2000, 2005) são mais bem compreendidos como efeitos do discurso, mudança de critérios de classificação da realidade numa interação complexa e passível de contestação entre mercados, conhecimento psiquiátrico e administração da saúde.

Há um movimento amplo de reconfiguração do quadro cognitivo quando o assunto é a saúde; novas esferas de interinfluência, novos interesses e novas motivaçóes são engendrados. Se os medicamentos se apresentam como dispositivos biopolíticos de gestão de comportamentos cotidianos socialmente indesejados, eles cumprem esse papel multiplicando os lucros da indústria farmacêutica. As síndromes são tomadas, pela individualidade de cada paciente, como disfunçôes do cérebro a serem corrigidas numa perspectiva medicamentosa e apresentando o diagnóstico como algo merecido pelos diagnosticados. Este é o caso da reemergência do TDAH,

\section{Referências}

ARAÚJO, T. Verdades inconvenientes sobre a indústria de remédios. 2011. Disponível em: https://super.abril.com.br/saude/verdades-inconvenientes-sobre-a-industria-dos-remedios/. Acesso em: 20 mar. 2020.

ARIÈS, P. [1981]. História social da criança e da família. Tradução de Dora Flaksman. 2. ed. Rio de Janeiro: LTC, 2011.

BOURDIEU, P. As estruturas sociais da economia. Lisboa: Instituto Piaget, 2000.

BOURDIEU, P. O campo econômico. Política e Sociedade, Florianópolis, v. 4, n.6, p. 15-57, 2005.

BOURDIEU, P. A produção da crença. Contribuição para uma economia dos bens simbólicos. 3. ed. RGS: Zouk, 2006. 
BOURDIEU, P. O senso prático. Rio de Janeiro:Editora Vozes, 2009.

CAPONI, S. História do poder psiquiátrico.Ciência e Saúde Coletiva, v. 14, n. 1, p. 95-103, 2009a.

CAPONI, S. Biopolítica e medicalização dos anormais. Physis: Revista de saúde coletiva, v. 19, n. 2, p. 529-549, 2009b.

CAPONI, S. Emil Kraepelin and the problem of degeneration. História, Ciência, Saúde Manguinhos. Rio de Janeiro, v. 17, supl.2,p. 475-494, 2010.

CAPONI, S. O DSM como dispositivo de segurança. Physis: Revista de saúde coletiva, Rio de Janeiro, v. 24, n. 3, p. 741-763, 2014.

CAPONI, S. Vigiar e medicar: o DSM 5 e os transtornos ubuescos da infância. In:CAPONI, S.; VÁSQUEZ VALENCIA, M. F.; VERDI, M. (org.).Vigiar e medicar: estratégias de medicalização da infância. São Paulo: LiberArs, 2016. p. 29-46.

CAPONI, S. Uma sala tranqüila. Neurolépticos para uma biopolítica da indiferença. SP: LiberArs, 2019.

CONSELHO FEDERAL DE MEDICINA (CFM). Atualizaçáo de posicionamento conjunto: em defesa de boas práticas no relacionamento entre a classe médica e a indústria farmacêutica, 2017. Disponível em: http://portal.cfm.org.br/images/PDF/documento_interfarma.pdf. Acesso em: 16 jul. 2019ECKS, S.Eating drugs: Psychophamarceutical pluralism in India. NewYork: New York University Press, 2013.

EWALD, F. Norms, disciplines and the law. Representations, 30,Special Issue: Law and the Order of Culture, p. 138-161, 1990.Disponível em: https://www.jstor.org/stable/2928449? read-now=1\& refreqid=excelsior\%3A4250ff2d02326039647d0100aa23bb6e\&seq=10\#page_scan_tab_contents. Acesso em: 20 mar. 2020.

FIUZA, E. P. S.; LISBOA, M. B. Bens credenciais e poder de mercado: um estudo econométrico da indústria farmacêutica Brasileira. Technical report.Texto para discussão n. 846. Rio de Janeiro: IPEA, 2001.

FLIGSTEIN, N.; MARA-DRITA, I. How to make a market: reflections on the attempt to create a Single Market in the European Union.Am. Journal of Sociology, v. 102, n. 1, p. 1-33, 1996.

FLIGSTEIN, N. Mercado como política: uma abordagem político-cultural das instituições de mercado.Contemporaneidade e Educaçáo, ano 6, n. 9, p. 26-55, 2001 a.

FLIGSTEIN, N. Le mythe du marché.Actes de la Recherche, v. 139, n. 1, p. 3-12, 2001 b.

FOUCAULT, M. Os anormais: curso no Collège de France (1974-1975).São Paulo: WMF Martins Fontes, 2018.

FOURCADE, M. Cents and Sensibility: Economic Valuation and the Nature of "Nature". American Journal of Sociology, v. 116, n. 6, p. 1721-1777, 2011. 
FOURCADE, M.; HEALY, K. Seeing like a market. Socio-EconomicReview, v. 15, n. 1, p. 9-29, 2017.

FRANCES, A. Voltando ao normal. Como o excesso de diagnósticos e a medicalização da vida estão acabando com a nossa sanidade e o que pode ser feito para retomarmos o controle. 1. ed. Rio de Janeiro: Versal Editores, 2016.

FRANCES, A. Advice To DSM V.Change Deadlines And Text, Keep Criteria Stable. Psyquiatric Times, 26 aug. 2009. Disponível em: https://www.psychiatrictimes.com/view/advice-dsm-vchange-deadlines-and-text-keep-criteria-stable.Acesso em: 20 mar. 2020.

FIRST, M.; FRANCES, A. Issues for DSM-V. Unintended consequences of small changes: the case of paraphilias. Am J Psychiatry, v. 165, p.240-1241, 2008. Disponível em: https://ajp. psychiatryonline.org/doi/pdf/10.1176/appi.ajp.2008.08030361. Acesso em: 20 mar. 2020.

GAY, P. Freud. Uma vida para nosso tempo. São Paulo: Companhia das Letras, 1989.

HEALY, D.The new medical oikumene. In:PETRYNA, A.; LAKOFF, A.; KLEINMAN, A. (ed.). Global Pharmaceuticals. Ethics, Markets, Practices. Durham and London: Duke University Press, 2006. p. 61-84.

KANNER, L. [1972]. Child psychiatry. 4th ed. Springfield. IL: C. C. Thomas, 2000.

LAKOFF, A. Adaptative will: the evolution of attention deficit desorder. Journal of the History of the Behavioral Sciences, v. 36, n. 2, p. 149-169, 2000.

LAKOFF, A. Pharmaceutical reazon. Knowledge and value in global psychiatry. Cambridge University Press, 2005.

LAKOFF, A. High Contact, gifts and surveillance in Argentina. In:PETRYNA, A.; LAKOFF, A.; KLEINMAN, A. (ed.). Global Pharmaceuticals. Ethics, Markets, Practices. Durham and London: Duke University Press, 2006. p. 112-135.

LIEBERMAN, J.; OGAS, O.Psiquiatria - uma história não contada. 2. ed. São Paulo: WMF Martins Fontes, 2019.

LOPES, J. L. A psiquiatria na época de Freud. Rev Bras Psiquiatr, v. 23, n. 1, p. 28-33, 2001.

MARTINHAGO, F.; CAPONI, S. Breve história das classificaçôes em psiquiatria. R. Inter. Interdisc. INTERthesis, v. 16, n. 1, p. 74-91, 2019.

MARTINHAGO, F; CAPONI, S.; LAVAGNINIO, N. J.; FOLGUERA, G.; CAPONI, S. Risk factors and genetic bases: the case of attention deficit hyperactivity disorder. Salud Colectiva v. 15: e1952,2019. Disponível em: http://revistas.unla.edu.ar/saludcolectiva/article/view/1952/1445. Acesso em: 20 mar. 2020.

MAZON, M. S. Padrões de qualidade e segurança alimentar no terreno institucional brasileiro. Dados, v. 52, n. 4, p. 1003-1044, 2009.

MAZON, M. S. Indústria farmacêutica e psiquiatria no quadro da Sociologia Econômica: uma agenda de pesquisa. Política \& Sociedade, v. 18, p. 136-161, 2019. 
MAZON, M. S.; MOURA, W. G. Cachorros e humanos. Mercado de raçóes pet em perspectiva sociolólogica. Civitas. Revista de Ciências Sociais, v. 17 n. 1, p. 138-158, 2017.

PEARCE, J. Dr. Stella Chess, Child Development Specialist, Dies at 93. New York Times, 2007. Disponível em: https://www.nytimes.com/2007/03/22/nyregion/22chess.html. Acesso em: 20 mar. 2020.

PETRYNA, A.; LAKOFF, A.; KLEINMAN, A. Introduction. In:PETRYNA, A.; LAKOFF, A.; KLEINMAN, A. (ed.). Global Pharmaceuticals. Ethics, Markets, Practices. Durham and London: Duke University Press, 2006. p. 206-239.

POLS, H.; OAK, S. Bmed, F. War and Military Menthal Health. The US Psychiatric Response in the 20th. Century Am J Public Health, v. 97, n. 12, p. 2132-2142, 2007. Disponível em: https:// www.ncbi.nlm.nih.gov/pmc/articles/PMC2089086/.Acesso em: 20 mar. 2020.

ROBERTS, L. W.; LOUIE, A. K. Guia de estudos para o DSM-5. Tradução deRegis Pizzato. Porto Alegre: Artmed; 2017.

VEJA.Déficit de atenção atinge 4,4\% de crianças e adolescentes, Veja - Educação, nov. 2011. Disponível em: https://veja.abril.com.br/educacao/deficit-de-atencao-atinge-44-de-criancas-eadolescentes/. Acesso em: 20 mar. 2020.

VIANA, A. L. A. As políticas de saúde nas décadas de 80 e 90: o longo período das reformas. In:CANESQUI, A. M. (org.).Ciências Sociais e Saúde para o ensino médico. São Paulo: Fapesp; Hucitec, 2000. p.113-133.

WHITE, W. Thomas And Chess: Temperament Type Longitudinal Study And Findings, Better Help, 2020, Disponível em: https:/www.betterhelp.com/advice/temperament/thomas-and-chesstemperament-type-longitudinal-study-and-findings/. Acesso em: 20 mar. 2020.

WHITAKER, R. Anatomia de uma pandemia. Pílulas Mágicas, drogas psiquiátricas e o aumento assombroso da doença mental. Rio de Janeiro: Editora Fiocruz, 2017.ZELIZER, Viviana. Economic lives: how culture shapes the economy. Princeton University Press, 2011.

ZELIZER, V. [1985]. Princing de priceless child. The changing social value of children. Princeton University Press: [S.l.], 1994. 


\section{From diagnostics to manuals: pharmaceutical market and childhood mental disorders in question}

\section{Abstract}

The purpose of the article is to situate the moment of change - both in articles and in research procedures - that marks DSM-III as a way of approaching psychiatric disorders, placing the pharmaceutical industry in the making of new discourses. This is the moment for the reemergence of Attention Deficit Hyperactivity Disorder (ADHD) and marks the confrontation with the Freudian psychodynamic approach that will be supported by the alternative of tests and statistical procedures. What is the context of these changes? We mobilize authors from economic sociology to think of the drug market as a field of struggle - struggle around the criteria for classifying reality - as well as the dynamics of interaction with the field of health. The article starts from bibliographic research and document analysis. The argument is that the nosology of ADHD, like any other cultural arbitrary, is not neutral and expresses power relations. If several researches point to medical power as biopolitical power, it is possible to see how new arrangements between the pharmaceutical industry and psychiatry expand the scope of the first to reach adolescence and childhood, adding the role of the pharmaceutical industry as biopolitical reinforcement

Keywords: Market.Diagnosis. Childhood menthal disorders. ADHD. Pharmaceutical industry. 